\title{
25 Research Soure \\ Integrated Input-Output and Systems Analysis Modelling: The Case of Tunisia.Part 1 - Energy technology Input- Output multipliers
}

\author{
Mark Howells \\ Imperial College London \\ Thameur Necibi \\ Institut Tunisien de la Compétitivité et des Etudes Quantitatives \\ John Skip Laitner \\ Economic and Human Dimensions Research Associates \\ Francesco Gardumi ( $\sim$ gardumi@kth.se ) \\ Kungliga Teckniska Högskolan \\ Franziska Bock \\ Deutsche Gesellschaft für Internationale Zusammenarbeit (GIZ) GmbH
}

\section{Method Article}

Keywords: Energy-Economy, Jobs, Energy Efficiency, Renewables, Input-Output, Tunisia

Posted Date: March 25th, 2021

DOI: https://doi.org/10.21203/rs.3.rs-336989/v1

License: (c) (i) This work is licensed under a Creative Commons Attribution 4.0 International License. Read Full License 


\section{Abstract}

This paper examines four simple stereotypical electricity-sector investments and estimates selected direct and indirect job impacts. To do so, the analysis focuses on the development of a simple Input-Output model and generic financial descriptions of energy efficiency and renewable energy interventions. These are applied to the Tunisian electricity sector. Sensitivities are developed around the assumptions required to calibrate the resulting financial flows. All aspects of this analysis are open source and drawing from ubiquitously available social accounting matrices, with the aim of increasing their scalability and lowering the threshold of energy-economy modelling. This analysis is used to develop intermediate data for a dynamic systems model as well as to produce selected policy insights. They relate to: the payback period associated with energy efficiency investments; local content; capital intensity; and implications on gas (for power generation) imports. Associated with this are policy recommendations that relate to the choice of new power generation, the scheduling of energy efficiency programs and defining future data needs to better calibrate the analysis of those interventions.

\section{Introduction}

This methodology paper is the first in a series of two. It develops job creation multipliers associated with energy supply and energy efficiency (EE) investments and it quantifies the multipliers for the case of Tunisia. The analysis is static and developed with the use of generic descriptions of financial flows. Both the model and generic descriptions can be easily translated to other settings, or refined for the analysis at hand. In part two of the paper they are introduced into a dynamic energy systems model. Figure 1 shows the scope of the paper series and, highlighted in blue, the scope of this paper.

Energy systems models are commonly employed to analyse future system configurations. The scenarios that they describe are typically thermodynamically consistent configurations of the components of an energy system to meet one or several objectives, such as minimising cost while achieving sector-specific climate targets. Minimising cost is a common objective as it reflects the reality that financial resources are limited and getting lower service costs to an economy can increase its effectiveness. The cost for energy system infrastructure is typically funded via taxes or the tariff of energy sales. Accordingly, the more expensive the energy system, the higher the cost to the consumer. With increasing costs and under restricted budgets, the less money is spent on other inputs needed to produce things.

Thus, the energy system configuration is important. Depending on how the configuration changes over time, as noted above, so do the occurring costs and levels of imports and exports of building materials or components for the construction of new facilities as well as fuel sources. If imports are relatively expensive, money in consequence is lost from the economy. There are also shifts in the levels of local construction and investment: If local construction is maximised, there are more direct local jobs. The same is true for the supply of local construction content.

Thus, capturing the systems configuration and understanding its implications is important. Moving beyond minimising that systems' cost (which is the domain of the energy systems model), it is the subject of this paper to understand the wider economic impacts.

We need a method for understanding broad economic impacts as this is often the focus of national policy. This needs to be more encompassing than just considering least cost; it needs to be systematically sound; and it needs to be detailed enough to capture peculiar characteristics of the analysed economy. In this way, beyond 
understanding the immediate economic and job effects, decision-makers gain insights into the structural consequences of the energy transition and recognise levers for shaping it in a way that fosters the development of a national green economy.

In this paper we do so by introducing and adding Input-Output modelling to provide broader insights.

An important motivation for this analysis is the relevance to the energy strategy of Tunisia. The National Appropriate Mitigation Action (NAMA) of Tunisia aims at 34\% reduction of final energy consumption mostly by means of EE measures [1]. The Tunisian Solar Plan, long-term renewable energy plan of the country, targets $30 \%$ share of renewable energy (RE) in electricity supply by 2030 [2]. This is to be achieved mainly with deployment of wind and solar capacity. However, the study is of more general interest and application. From a system perspective EE is often low cost and economical (although it comes with the need for strong and continuous institutional support). Further, the costs of wind and solar power have been dropping rapidly (although there is need for a flexible system to balance wind and solar intermittency). Given the importance of EE, wind and solar, this paper develops a simple model of the financial flows associated with deploying them. It then goes on to track the compound effects that ripple through the economy as a result.

The rest of the paper presents the context and literature background; then it moves to the methods employed in this work; finally, it applies the methods to Tunisia, through a test case study, and discusses insights and limitations of the approach.

\subsection{Context}

The Tunisian real economy has traditionally relied upon agricultural and fishery production, tourism, abundance of phosphate resources and diversified industrial production (textiles, chemicals and aeronautics) [3]. It is highly grounded on qualified labour. In recent years, GDP growth has slowed down, initially due to the crisis in Libya. Libya has been the main trade partner, especially for agro-food products and construction [4]. Growth had also been hampered by a slowdown in agriculture, as well as a contraction in oil and gas industry [5]. In the years to come, a gradual recovery is expected, especially due to agriculture, manufacturing and tourism, as well as increased domestic gas production.

While poverty has greatly decreased in the past decade, since 2014 unemployment has been rising. It set around $15 \%$ in 2017 , with much higher rates among young graduates and women [4]. Job creation is weak and there still exists significant inequality in the labour market.

The energy sector has so far relied mostly on natural gas [6]. Around $45 \%$ of the need for natural gas in the country was met by imports (mainly from Algeria) in 2019. The rest was produced locally.

In this context, we deem it of high relevance and timely to create tools to transparently assess the employment effects of energy investments and energy supply decisions.

\subsection{Literature background}

A study by GIZ and the National Agency for Energy Management (ANME) of Tunisia quantified potential job creation through the investments in renewable energy technologies and EE measures envisioned by the Tunisian Solar Plan (PST) [7]. It focuses on solar water heaters, wind turbines, concentrating solar power, solar PV and EE in buildings and industry. Investments in these technologies as calculated in a previous study by Lechtenbömer et al. 
[8] are fed into an Input-Output model. The study lays the ground for the present work. However, the methodology used does not allow for dynamic optimisation of the technology investments and the tools are not fully open source. We intend to follow an approach in some instances similar, but also generalise it and make it available as a low-threshold open source methodology.

Methodologies for linking energy systems and economy-wide analyses have been developed in the past decades, using Input-Output (IO) models, econometric models, Computable General Equilibrium (CGE) models or a combination thereof. Here, we focus on studies using IO models. Laitner et al. authored early work on understanding the economy-wide impacts of national energy and climate policies [9]. They feed the outputs of energy investment scenarios considering policy and technology innovations (run in NEMS, National Energy Modeling System) into an Input-Output model (IMPLAN, IMpact analysis for PLANning), to assess the impacts in terms of GDP, sectoral outputs and employment. Howells et al. present a multi-criteria analysis to assess the implications of selected EE measures on sustainable development objectives in South Africa [10]. Using Input-Output analysis, employment and rebound effects of EE measures are computed. These effects are fed as coefficients (effects per unit of energy saved) to an energy investments and alternatives model in MARKAL. The model is then run to optimise the extent of EE interventions, based on a set of sustainable development objectives, properly weighed. Winkler et al. propose an approach to support developing countries in elaborating Sustainable Development Policies and Measures (SDPAMs) [11]. They analyse effects of EE measures on electricity generation and related emissions, jobs and health. The work constitutes one of the early attempts to combine energy system optimisation and IO analysis with focus on EE measures in the industrial sector. It builds on the methodology by Howells et al. [10]. Net employment effects through the economy due to unit energy savings from efficiency measures are included in an energy investments optimisation model in MARKAL. However, the employment effects are computed based only on a snapshot of the economy. Howells et al. analyse emission rebound effects of investments in the power sector in South Korea [12]. They build on the methodology by Winkler et al. [11]. They first calculate changes in demand for electricity in the economy due to investments in a new nuclear power plant replacing an LNG plant. Then they feed marginal changes back to an energy system model (MESSAGE), so that the demand becomes dependent on the structure of the supply. Radi recently developed an energy-economy model application to Egypt [13]. Outputs of an energy investment model set up in OSeMOSYS are used as inputs to an Input-Output model using the EORA 26 IO Tables (2015), to assess economy and job impacts of energy investments. The 'Water-Gas'Electricity' sector of the EORA tables is disaggregated to show the economic flows between each individual technology type in the electricity sector with all other sectors. The disaggregation is based on an approach by Lindner et al. [14] and on own assumptions by the author.

In this work, we build on the methods by Howells et al. and by Winkler et al. [10], [11], which have the benefit of allowing simple and dynamic assessment of employment effects as a function of energy investment choices, directly within an energy investments optimisation tool. We advance the methods by assessing employment effects of EE measures and power supply investments jointly.

The GDP and employment coefficients are still calculated based on a snapshot of the economic structure (in a base year). As a first step to overcome this limitation, we create a fully open source and modular framework, that can be developed towards a recursive structure in future efforts.

\section{Models And Methods}


The development of the Leontief multipliers follows a standard approach. We describe it in the next sections step by step, with pointed reference to the supplementary online material.

\subsection{A-Matrix}

We start from the latest publicly available IO model of the Tunisian economy, from OECD [15]. This can be found in the sheet labelled Tunisia 10 Table 2015 in the supplementary material. It is the table of domestic outputs and inputs for the year 2015. 35 sectors are considered. The source is used as it contains the most recent publicly avilable 10 for the country. And, importantly it is available for 64 countries and data is harmonised, allowing analysis to be easily scaled. However, a key limitation is that electricity, gas, water supply, sewerage, waste and remediation services are combined into a single sector. Thus, distinguishing between the relative productivity of electricity and gas is immediately impossible. This poses a useful direction for the extension of this work.

In sheet A-Matrix the A-Matrix is calculated. We do so by dividing purchases (the columns) with the total output of each sector. The matrix indicates the relative input for each unit of output per sector (recall all units are monetary). Note also that as we consider domestic output and imports, we account for the loss from the economy associated with exports.

\subsection{Leontief inverse matrix: (I-A)-1}

The Leontief inverse matrix is calculated by minusing the Identity Matrix in the sheet Identity-Matrix in the supplementary material from the A Matrix in the intermediate sheet Id-A Matrix. The Id-A Matrix is inverted in order to derive the Leontief inverse matrix in the sheet Leontief Inverse. In each entry, the compound effects of one dollar of output are measured in that sector. By summing up the columns, the economy wide impact is measured. The economy wide impact is called a multiplier. The economy wide change in spending in, or expenses from one of those sectors can now be measured. Those sectors and the economic multipliers calculated are summarised in Table 1. 
Table 1

Sectors considered in the 10 Analysis - and the derived multiplier - for Tunisia.

Economic Sector Considered

DOM_01T03: Agriculture, forestry and fishing

DOM_05T06: Mining and extraction of energy producing products

DOM_07T08: Mining and quarrying of non-energy producing products

DOM_09: Mining support service activities

DOM_10T12: Food products, beverages and tobacco

DOM_13T15: Textiles, wearing apparel, leather and related products

DOM_16: Wood and of products of wood and cork (except furniture)

DOM_17T18: Paper products and printing

DOM_19: Coke and refined petroleum products

DOM_20T21: Chemicals and pharmaceutical products

DOM_22: Rubber and plastics products

DOM_23: Other non-metallic mineral products

DOM_24: Manufacture of basic metals

DOM_25: Fabricated metal products, except machinery and equipment

DOM_26: Computer, electronic and optical products

DOM_27: Electrical equipment

DOM_28: Machinery and equipment n.e.c.

DOM_29: Motor vehicles, trailers and semi-trailers

DOM_30: Other transport equipment

DOM_31T33: Other manufacturing; repair and installation of machinery and equipment $\quad 1.52$

DOM_35T39: Electricity, gas, water supply, sewerage, waste and remediation services 1.52

DOM_41T43: Construction

DOM_45T47: Wholesale and retail trade; repair of motor vehicles

DOM_49T53: Transportation and storage

DOM_55T56: Accomodation and food services

DOM_58T60: Publishing, audiovisual and broadcasting activities

DOM_61: Telecommunications

DOM_62T63: IT and other information services

DOM_64T66: Financial and insurance activities

DOM_68: Real estate activities
Economic Multiplier

1.51

1.43

1.44

1.45

1.96

1.51

1.74

1.65

1.73

1.66

1.47

1.63

1.56

1.44

1.46

1.45

1.43

1.46

1.41

1.61

1.42

1.46

1.68

1.66

1.53

1.46

1.49

1.25 


\begin{tabular}{|ll|}
\hline Economic Sector Considered & Economic Multiplier \\
\hline DOM_69T82: Other business sector services & 1.43 \\
\hline DOM_84: Public administration and defence; compulsory social security & 1.38 \\
\hline DOM_85: Education & 1.29 \\
\hline DOM_86T88: Human health and social work & 1.44 \\
\hline DOM_90T96: Arts, entertainment, recreation and other service activities & 1.58 \\
\hline DOM_97T98: Private households with employed persons & 1.00 \\
\hline
\end{tabular}

In order to account for changes, we need to identify the sectors that we assume will be impacted as a result of a change in investment in the energy sector. The change, positive - or negative - is then multiplied with the multiplier to derive the total economic impact. Then, given a fixed ratio of jobs per economic activity (depending on the assumed average wage and the wage share of value added), job impacts are estimated for each intervention.

Changes in economic flows (and the assumptions that underpin them) are now described. They begin with power plants and follow with an EE intervention.

\subsection{Economic flows associated with changes in the energy sector}

Economic flows are accounted for in the Input-Output model and are illustrated in Fig. 2. We are interested in several aspects, including local payment for goods and services. Local payments circulate in the economy (resulting in positive multipliers). Foreign payments leave the economy (resulting in no multiplicative impacts in the local economy). For later integration with the energy system, the Open Source energy Modelling System (OSeMOSYS) [16] will be used in part two of this work. OSeMOSYS accounts for non-energy flows per unit of activity (typically energy used or produced).

Thus we calculate job-years per unit of energy (PJ). For a power plant, this is in terms of electricity produced. For an EE measure, this is per-unit of electricity-use reduced. As OSeMOSYS is not static, it will dynamically calculate aspects of the energy system determining the relative units of energy produced or - via EE - saved. And, even if not using OSeMOSYS and using a similar tool to determine such quantities, normalising the multipliers might help create a sense of relative perspective.

\subsubsection{Economic flows associated with power plant construction}

Figure 2 illustrates the money flows between sectors when a new power plant is constructed and run. They are described in the text following, the economic sectors highlighted and parameterised thereafter. Note that this model of economic flows for power sector investment was developed in the peer reviewed literature for South Korea [12], South Africa [10] and is adapted for Tunisia here.

There are several economic flows that we shall account for when considering a power plant. They are described below with number labels mapped to Fig. 2 and they refer to a generic gas power plant.

1. Money flowing to the construction industry for the installation. Construction will be the size of the investment, multiplied by the capital cost, multiplied by the local content of that construction. 
Construction $=$ Capacity $*$ Capital Cost $*$ Local content

The size of the investment will be the capacity required to generate 1 PJ of electricity. The capacity (if running at $100 \%$ ) needed to produce a unit of electricity in our model is referred to as the capacity-to-activity unit. But the power plant will be running at a load factor of less than $100 \%$. Thus, the size of the actual capacity to be invested in (for generating 1 PJ of electricity) will equal the capacity-to-activity unit divided by the power plant load factor.

Capacity = CapacityToActivityUnit / Plant Load Factor

2. Money flowing into the maintenance will equal the maintenance cost per unit of capacity. That is a common unit in which maintenance is measured. It is also assumed that maintenance is performed locally. Money flowing from the electricity sector to pay for maintenance will in turn be reflected by the marginal tariff increase taken from the rest of the economy.

Maintenance $=$ Capacity * $0 \& M$ Cost

3. Money flowing out of the electricity sector in order to pay for construction will be equal to the cost of the installation multiplied by the fraction that paid from equity from the power sector. The cost of the installation will equal the size of the investment multiplied by its capital cost.

Elec. $($ Constr $)=$ Capacity * Capital Cost * Equity

4. Money flowing from the electricity sector to pay for fuel will equal the quantity of fuel used multiplied by its cost multiplied by the fraction of that fuel which is bought locally. This is equal to zero in wind and solar power plants. This cost will be reflected in the tariff that is charged to the rest of the economy.

Elec. $($ Fuel pay) $=1 /$ Efficiency * Fuel Price

5. Money flowing from the finance industry to pay for the capital investment will be equal to the cost of the installation multiplied by the fraction that paid from debt.

Fin. $($ Constr $)=$ Capacity * Capital Cost * Debt

6. The cost of the installation will equal the size of the investment multiplied by its capital cost.

Installation = Capacity * Capital Cost

7. Money flowing from the electricity sector to pay for the debt financing will be equal to the amount borrowed (in 5) multiplied by the payment factor, which is a function of the economic life of the power plant and the cost of debt.

Finance $=$ Fin $($ Const $) *$ Payment Factor

8. Money flowing from the electricity sector to pay for the equity financing will be equal to the amount paid for from equity (in 3) multiplied by the payment factor, which is a function of the economic life of the power plant and the cost of equity.

Page $8 / 30$ 
Elec. $($ Repayment $)=$ Elec. $($ Constr $) *$ Payment Factor

9. Money flowing to the gas sector to pay for fuel will equal the payment for fuel multiplied by the fraction of the gas that is locally procured. This is equal to zero in wind and solar power plants. It will be derived from the tariff (paid for by the economy).

Gas (Fuel buy $)=$ Elec. $($ Fuel pay $) *(1-\%$ Import $)$

10. Payment for local fuel purchases will be recycled into the economy while payments for imports will not.

11. Payment for local construction will be recycled into the economy while payment for foreign components will not.

For solar and wind power plants a similar system is employed with the exception that fuel related purchases are not included, as the fuel is free.

There are compounding impacts for each of the money flows. These are estimated by multiplying the money flow with the economic multiplier of the relevant sector. The so calculated impact on the GDP is further multiplied by a fixed rate of $\mathrm{N}$ jobs per unit economic activity of each sector, to obtain an overall impact on jobs.

For reference, the specific economic sectors considered for a power plant investment are outlined in Table 2. 
Table 2

Sectors considered in the power plant analysis.

Economic sector
DOM_01T03:
Agriculture, forestry and
fishing

DOM_05T06: Mining and extraction of energy producing products

D0M_07T08: Mining and quarrying of nonenergy producing products

DOM_09: Mining support service activities

DOM_10T12: Food products, beverages and tobacco

DOM_13T15: Textiles, wearing apparel, leather and related products

DOM_16: Wood and of products of wood and cork (except furniture)

DOM_17T18: Paper products and printing

DOM_19: Coke and refined petroleum products

DOM_20T21: Chemicals and pharmaceutical products

DOM_22: Rubber and plastics products

DOM_23: Other nonmetallic mineral products

DOM_24: Manufacture of basic metals

DOM_25: Fabricated metal products, except machinery and equipment

DOM_26: Computer, electronic and optical products

\section{Sectors considered (and for what)}

Assumed tariff increases affect all sectors. Increases are spread as a weighted average of electricity consumption through the economy. 
DOM_27: Electrical

equipment

DOM_28: Machinery and equipment n.e.c.

DOM_29: Motor vehicles, trailers and semi-trailers

DOM_30: Other transport equipment

DOM_31T33: Other manufacturing; repair and installation of machinery and equipment

DOM_35T39: Electricity, gas, water supply, sewerage, waste and remediation services

DOM_41T43:

Construction

DOM_45T47: Wholesale and retail trade; repair of motor vehicles

DOM_49T53:

Transportation and storage

DOM_55T56:

Accomodation and food services

DOM_58T60:

Publishing, audiovisual

and broadcasting

activities

DOM_61:

Telecommunications

DOM_62T63: IT and other information services

DOM_64T66: Financial and insurance activities

Captures all expenditure from debt onto construction. And all income from the power sector (collected from the tariff for debt repayment).

Sector into which payments go for the operating and maintenance of the power plant.

Captures all expenditure on fuel and income to the power sector from the tariff increase.

Captures all construction required for building the power plant

DOM_68: Real estate activities

DOM_69T82: Other

business sector services 


\begin{tabular}{|c|c|}
\hline Economic sector & Sectors considered (and for what) \\
\hline \multicolumn{2}{|l|}{$\begin{array}{l}\text { DOM_84: Public } \\
\text { administration and } \\
\text { defence; compulsory } \\
\text { social security }\end{array}$} \\
\hline \multicolumn{2}{|l|}{ DOM_85: Education } \\
\hline \multicolumn{2}{|l|}{$\begin{array}{l}\text { DOM_86T88: Human } \\
\text { health and social work }\end{array}$} \\
\hline \multicolumn{2}{|l|}{$\begin{array}{l}\text { DOM_90T96: Arts, } \\
\text { entertainment, } \\
\text { recreation and other } \\
\text { service activities }\end{array}$} \\
\hline $\begin{array}{l}\text { DOM_97T98: Private } \\
\text { households with } \\
\text { employed persons }\end{array}$ & \\
\hline
\end{tabular}

\subsubsection{Economic assumptions associated with power plant investments}

The assumptions that underlie the economic flows calculated are summarised below, for all main technologies freely invested in, in the model. Note that the model is developed such that each of these can be updated by the analyst. 
Table 3

Power plant assumptions used.

\begin{tabular}{|c|c|c|c|c|c|c|c|}
\hline $\begin{array}{l}\text { Power Plant } \\
\text { Intervention }\end{array}$ & $\begin{array}{l}\text { Solar } \\
\text { PV }\end{array}$ & CSP & $\begin{array}{l}\text { Wind } \\
\text { onshore }\end{array}$ & $\begin{array}{l}\text { Wind } \\
\text { offshore }\end{array}$ & $\begin{array}{l}\text { Gas } \\
\text { Open } \\
\text { Cycle }\end{array}$ & $\begin{array}{l}\text { Gas } \\
\text { Combined } \\
\text { Cycle }\end{array}$ & Source \\
\hline PJ Elc out (PJ) & 1 & 1 & 1 & 1 & 1 & 1 & \\
\hline Efficiency \% & $100 \%$ & $100 \%$ & $100 \%$ & $100 \%$ & $36 \%$ & $54 \%$ & $\begin{array}{l}\text { Tunisian } \\
\text { utility }\end{array}$ \\
\hline Fuel price MUSD/PJ & - & - & - & - & 6.98 & 6.98 & $\begin{array}{l}\text { Tunisian } \\
\text { utility }\end{array}$ \\
\hline$\%$ import & - & - & - & - & $60 \%$ & $60 \%$ & Assumed \\
\hline Cap:Act unit & 31.536 & 31.536 & 31.536 & 31.536 & 31.536 & 31.536 & Calculated \\
\hline Load factor \% & $15 \%$ & $45 \%$ & $28.3 \%$ & $35.3 \%$ & $88 \%$ & $85 \%$ & $\begin{array}{l}\text { Tunisian } \\
\text { utility }\end{array}$ \\
\hline Capacity (GW) & 0.21 & 0.07 & 0.11 & 0.09 & 0.04 & 0.04 & Calculated \\
\hline CapCost (MUSD/GW) & $800 \downarrow$ & $4700 \downarrow$ & 1300 & 2964 & 642 & 950 & $\begin{array}{l}\text { Tunisian } \\
\text { utility }\end{array}$ \\
\hline Local content & $10 \%$ & 10 & $10 \%$ & $10 \%$ & $10 \%$ & $10 \%$ & Assumed \\
\hline $\begin{array}{l}\text { Fixed O\&M costs } \\
\text { (MUSD/GW) }\end{array}$ & 20.0 & 41.1 & 39.0 & 88.9 & 10.8 & 8.52 & $\begin{array}{l}\text { Tunisian } \\
\text { utility }\end{array}$ \\
\hline $\begin{array}{l}\text { Variable O\&M costs } \\
\text { (MUSD/GJ) }\end{array}$ & - & 1.39 & 2.22 & 2.22 & 0.65 & 0.39 & $\begin{array}{l}\text { Tunisian } \\
\text { utility }\end{array}$ \\
\hline $\begin{array}{l}\text { Total O\&M Costs } \\
\text { (MUSD/PJ) }\end{array}$ & 4.2 & 4.3 & 6.59 & 10.28 & 1.04 & 0.71 & Calculated \\
\hline Econ life (Years) & 25 & 30 & 25 & 25 & 30 & 30 & $\begin{array}{l}\text { Tunisian } \\
\text { utility }\end{array}$ \\
\hline Interest rate & 0.05 & 0.05 & 0.05 & 0.05 & 0.05 & 0.05 & Assumed \\
\hline$\%$ borrowed & $75 \%$ & $75 \%$ & $75 \%$ & $75 \%$ & $75 \%$ & $75 \%$ & Assumed \\
\hline Payment factor debt & 0.07 & 0.07 & 0.07 & 0.07 & 0.07 & 0.07 & Calculated \\
\hline$\%$ equity & $25 \%$ & $25 \%$ & $25 \%$ & $25 \%$ & $25 \%$ & $25 \%$ & Assumed \\
\hline Payment factor equity & 0.07 & 0.07 & 0.07 & 0.07 & 0.07 & 0.07 & Assumed \\
\hline $\begin{array}{l}\text { Assumed Average } \\
\text { Wage (TND) }\end{array}$ & 32,876 & 32,876 & 32,876 & 32,876 & 32,876 & 32,876 & Assumed \\
\hline $\begin{array}{l}\text { Assumed Average } \\
\text { Wage (USD) }\end{array}$ & 16,761 & 16,761 & 16,761 & 16,761 & 16,761 & 16,761 & $\begin{array}{l}2015 \\
\text { exchange } \\
\text { rate }\end{array}$ \\
\hline $\begin{array}{l}\text { Wage share of value } \\
\text { added. }\end{array}$ & $40 \%$ & $40 \%$ & $40 \%$ & $40 \%$ & $40 \%$ & $40 \%$ & Assumed \\
\hline Tariff (USD/kWh) & 0.07 & 0.07 & 0.07 & 0.07 & 0.07 & 0.07 & [17] \\
\hline
\end{tabular}


Techno-economic assumptions such as costs and efficiencies are the same as in the energy system model (and described in detail in part two of this paper). Those shown here refer to 2015 values. They were all collected in collaboration with the Tunisian electricity and gas utility STEG (Société Tunisienne de l'Electricité et du Gaz) and with a consortium of local institutions involved in energy research and decision making. A downward facing arrow indicates decreasing numbers over the years (used for the dynamic energy modelling part of the study).

The price of natural gas is provided by STEG and is an average of the price of domestic and imported gas, weighted over their current share in the primary energy mix. The local content is assumed upon consultation with local experts through 2020 and is considerably conservative compared to 2012 estimates for the same context ([7], pp 67). The electricity tariff is taken from a 2016 study by RES4MED [17]. It is used for calculation of the cost of saved electricity in MUSD/PJ. Very recent studies indicate that the local content for renewable technologies may be higher and that electricity sale tariffs for solar and wind installations may be from $15 \%$ to more than $50 \%$ lower than those indicated above. It is therefore important to use the current modelling framework as a live model, to be continuously updated by local users. Other parameters are assumed by the authors, in the absence of up-to-date information. They are used as a reasonable starting point, but they are meant to be changed by the user. Most are highly uncertain; therefore they need to be adjusted parametrically. An example will be given in Sect. 3. The full analysis with all calculations can be found in the annexed material.

\subsubsection{Economic flows for energy efficiency investments}

For energy efficiency, we consider three archetypal interventions. They are for industry, commerce and the residential sectors. Industry and buildings are both mentioned as key areas for mitigation in the Nationally Appropriate Mitigation Action of Tunisia [1]. In industry, the cement production has the highest emissions and presents high emission reduction potential, through fuel shifts, changes in cement composition, use of renewable energy and changes in buildings shells. Buildings (including both residential and commercial) are projected to be the highest GHG emitter by 2020. Targeted emissions reduction measures include thermal insulation. Figure 3 illustrates the money flows between sectors when an EE program is put in place. They are described in the text following, the economic sectors highlighted and parameterised thereafter. Note that this approach for assessing EE with an IO was initially developed in the peer reviewed literature by several authors [10], [18] and is adopted below.

For investments in EE, a similar pattern as for investments in power plants is followed. Money flows considered are summarised below with number labels referring to Fig. 6:

1. Money flowing to the construction industry for the EE installation(s). Underlying assumptions to this is that the installation of EE measures is all carried out within the construction sector. The gross expenditure per unit of energy reduced will equal the cost of the energy saved multiplied by the measure's 'payback period'. The local construction costs are multiplied by the local content of that construction.

Investment $=$ Cost of PJ saved * Payback Period * Local content

2. Money spent on institutions in order to support, monitor and verify the EE program. This is assumed to be a ratio of the capital cost of the intervention. That money derives from increased government spending. It is assumed to be a fraction of the cost of implementing the EE measure.

Program spend $=$ Cost of PJ saved * Program cost ratio

Page $14 / 30$ 
3. Money flowing out of the energy using (and reducing) sector in order to pay for construction will be equal to the cost of the installation multiplied by the fraction that paid from equity from that sector. The cost of the installation will equal the (per unit) cost of the energy multiplied by the measure's 'payback period'.

Down payment $=$ Cost of PJ saved * Payback Period * (1-\%Debt)

4. Money flowing from the finance industry to pay for the capital investment will be equal to the cost of the installation multiplied by the fraction that paid from debt (the cost of the installation will equal the size of the investment multiplied by its capital cost).

Loan payment $=$ Cost of PJ saved * Payback Period * \% Debt

5. Money flowing from the end-use sector to pay for the financing will be equal to the amount borrowed (in 4) multiplied by the payment factor which is a function of the economic life of the loan period.

Financing $=$ Loan payment * Payment Factor

6. Savings to the targeted end-use sector will equal the per-unit cost of energy over the lifetime of the EE measure.

7. Losses to the electricity sector will equal the savings to the targeted sector.

8. Given that marginal electricity production in Tunisia is based on imported gas and imported gas turbines, it is assumed that reductions in electricity sales for (7) will result in a high proportion of money lost to the economy via imports.

9. Non-marginal exports will be captured as usual as losses in the current electricity sector.

10. Similarly, a fraction of the EE measure will be locally constructed. The higher this fraction, the higher the quantity of money recycled in the local economy.

For each money flow there are compounding impacts. These are estimated by multiplying the money flow with the economic multiplier of the relevant sector. The so calculated impact on the GDP is further multiplied by a fixed rate of $\mathrm{N}$ jobs per unit economic activity of each sector, to obtain an overall impact on jobs. For reference, the specific economic sectors considered for the EE interventions are outlined below. 
Table 4

Sectors considered in the energy efficiency analysis.

Economic sector

Sectors considered (and for what)

D0M_01T03: Agriculture,

forestry and fishing

D0M_05T06: Mining and extraction of energy

producing products

DOM_07T08: Mining and quarrying of non-energy producing products

DOM_09: Mining support service activities

DOM_10T12: Food products, beverages and tobacco

DOM_13T15: Textiles, wearing apparel, leather and related products

DOM_16: Wood and of products of wood and cork (except furniture)

DOM_17T18: Paper products and printing

DOM_19: Coke and refined petroleum products

DOM_20T21: Chemicals and pharmaceutical products

DOM_22: Rubber and plastics products

DOM_23: Other nonmetallic mineral products

DOM_24: Manufacture of basic metals

DOM_25: Fabricated metal products, except machinery and equipment

DOM_26: Computer, electronic and optical products

DOM_27: Electrical equipment

DOM_28: Machinery and equipment n.e.c.

Reduction in energy bills due to energy efficiency in industry. (Weighted average based on consumption) 
DOM_29: Motor vehicles, trailers and semi-trailers

DOM_30: Other transport equipment

DOM_31T33: Other manufacturing; repair and installation of machinery and equipment

DOM_35T39: Electricity, gas, water supply, sewerage, waste and remediation services

DOM_41T43:

Construction

DOM_45T47: Wholesale and retail trade; repair of motor vehicles

DOM_49T53:

Transportation and storage

DOM_55T56:

Accommodation and food services

DOM_58T60: Publishing, audiovisual and broadcasting activities

DOM_61:

Telecommunications

D0M_62T63: IT and other information services

DOM_64T66: Financial

and insurance activities

DOM_68: Real estate activities

DOM_69T82: Other business sector services

D0M_84: Public administration and defence; compulsory social security

DOM_85: Education

DOM_86T88: Human health and social work
Reduction in demand due to energy efficiency in the Commercial sector. (Weighted average based on consumption)
Captures reduction in electricity purchases due to improved energy efficiency.

Captures all construction required for the energy efficiency measures
Captures all expenditure from debt onto construction. And all income from the power sector (collected from the tariff for debt repayment). 
DOM_90T96: Arts, entertainment, recreation and other service activities

DOM_97T98: Private households with Residential energy efficiency employed persons

\subsubsection{Economic assumptions associated with energy efficiency}

The parameterisation and assumptions that underlie the economic flows are summarised below. Note that the model is developed such that each of these can be changed and updated by the analyst.

Table 5

Energy efficiency program assumptions used.

\begin{tabular}{|lllll|}
\hline Generic Energy Efficiency Intervention & Residential & Commerce & Industry & Source \\
\hline Fraction of Reduced Sales as Exports / Growth & $50 \%$ & $50 \%$ & $50 \%$ & Assumption \\
\hline Assumed Payback Period (Years) & 6 & 5 & 4 & Assumption \\
\hline Avoided cost of electricity (MUSD/PJ) & 13.85 & 13.85 & 19.39 & Calculated \\
\hline Fraction Borrowed & $60 \%$ & $60 \%$ & $60 \%$ & Assumption \\
\hline Interest Rate & 0.05 & 0.05 & 0.05 & Assumption \\
\hline Period of Loan (Years) & 5 & 5 & 5 & Assumption \\
\hline Payment Factor & 0.23 & 0.23 & 0.23 & Calculated \\
\hline Assumed Average Wage (TND) & 32,876 & 32,876 & 32,876 & Assumption \\
\hline Assumed Average Wage (USD) & 16,761 & 16,761 & 16,761 & Assumption \\
\hline Wage share of value added. & $40 \%$ & $40 \%$ & $40 \%$ & Assumption \\
\hline Cost as Percent of annual saving & $1 \%$ & $1 \%$ & $1 \%$ & Assumption \\
\hline Local content & $20 \%$ & $20 \%$ & $20 \%$ & Assumption \\
\hline Tariff (USD/kWh) & 0.05 & 0.05 & 0.07 & [17] \\
\hline
\end{tabular}

The techno-economic assumptions for EE measures depend highly on the specific measures adopted. Most values were in this case assumed by the authors, based on experience from previous studies in South Africa [18]. The local content is assumed upon consultation with local experts and is decidedly conservative compared to 2012 estimates for the same context ([7], pp 67). While the values represent reasonable starting assumptions, the user is invited to perform sensitivity analyses around them. One such analysis is made for the local content Sect. 3. The electricity tariff is taken from a 2016 study by RES4MED [17]. It is used for calculation of the cost of saved electricity in MUSD/PJ.

\section{Results}


We show the direct economic flows for a gas, solar and wind power plant as well as an EE option, under the assumptions mentioned in previous sections.

Key variables of importance for each system are the degree of local content, the quantity of gas purchased locally (rather than imported) for the gas fired power plants and the capital costs. For instance, job gains associated with solar PV installations result much lower than those projected in the study by GIZ and ANME [7] and this is likely due to the cost of solar PV having decreased greatly in the past decade (if we consider all other assumptions fixed).

\subsection{Impact of economic assumptions on power plant investments}

We summarise the effect on job creation for five power plant configurations in Fig. 9. There are key observations made. Of interest is that:

- The lower the local content, the lower the number of local jobs created.

- The more gas that is bought externally, the higher the job losses.

- Gas typically results in job losses (when its feedstock is imported), while solar and wind in job gains.

This is consistent with the insights provided in Fig. 4 to 7. It must be noted that these results assume penetrations of variable renewables that are not as high as to require high supplementary investments for renewable integration on the grid. In cases with largely dominant variable renewable generation and related need for investments, the model would need to be adapted.

\subsection{Impact of economic assumptions on energy efficiency programs}

In the graphic below, job-years generated (per unit avoided electricity use) for residential EE measures are shown. They are plotted against different levels of local content and three payback times (1, 5 and 10 years). The assumption with the largest impact and of interest is the degree of local content on the program.

In order to maximise the job impacts of EE, a few key observations can be extracted from Fig. 10:

- The lower the payback the greater the number of jobs created.

- The higher the local content the greater the number of jobs created.

- For high payback interventions, high local content is required.

- Fast payback options can be initiated immediately even if implemented with imported skills and equipment.

- Longer payback period interventions have similar job creation potentials with higher local content (but negative impact with low local content). These should be targeted for local skills and development

Note that not reflected here is the strong institutional requirements to monitor, verify and learn as the EE program is in place. That is critical for at least two reasons. The first is that, unlike a power plant, solar or wind farm, an EE program cannot easily be seen. Thus it is necessary to ensure that its effect is clearly communicated to key stakeholders. Further, measures have to be actively managed, including their perceived impact. Their actual impacts need to be monitored in order to understand their impact on the energy system and emissions mitigation.

\section{Insights}


While an IO analysis is limited as it does not take into account substitutions that might take place outside of those conceived by the analysis, there are still policy-relevant insights that can be drawn from this framework. Those are summarised below:

- We note that EE interventions with fast payback periods should be initiated immediately, even if these have a low local content. That is because the gains to be made from reducing gas imports and new imported technology needed for power generation are great. Redirecting finance to these EE options has positive economic ramifications through the economy that result in employment increases.

- Energy efficiency interventions that have a slower payback period can have lower economic gains, if investments made are based on imported skills, technology and construction. This provides a strategic opportunity: Tunisia might position itself to identify where there is potential to increase the local content of such measures and actively develop an appropriate strategy to do so.

- Short payback implementation might be carried out aggressively while a strategic pathway is updated to tackle slower pay-back interventions, to maximise local impact.

- Similarly, where low cost renewable energy can be absorbed and displace new gas investment (that relies on imports), these investments should be prioritised.

- It is important to understand the limitations of RE displacement of gas-fired generation and increase the displacement potential. High variable RE interventions require balancing, congestion and other control issues. As volumes increase, expensive storage may be required. However, where integration costs are low, investment should be fast-tracked.

This study provides a simple basis for extension and more detailed analysis. Part of the data used is generic and systematic. This is useful for its explanatory potential. But as a result, it is limited compared to a more tailored and nationally specific study.

\section{Limitations And Next Steps}

All elements of this analysis can be ubiquitously Retrieved, Re-used, Reconstructed, Repeated this allows for Interoperability and Auditability (U4RIA) [19]. This paper applies an u4RIA approach in order to ensure FAIR (findability, accessibility, interoperability, reusability) scientific and sustainable development principles are applied [20].

While we derive important insights from the $\mathrm{IO}$ analysis, its static nature is incomplete and requires more formal dynamic analysis. To name a few changes that will take place with EE and RE investment that are not endogenously captured in an 10 analysis:

- Increased investment in one power plant option will be at the expense of another, unless demand is outstripping supply.

- Increased use of local resource will reduce purchases of imported gas and the relative proportions of each can depend on a number of factors.

- Purchases of imported gas result in leakage of money from the economy, economic and job losses. Investment in RE is therefore expected to have the dual impact of:

Increasing jobs from the RE investment and operation; Reducing job leakages with reductions in imports;

Page 20/30 
- However, increased investments in RE will require supplementary increases in investment in reserves. Those will incur relative costs.

- Investments in high (slow) payback EE appear to have negative effects, but these are lower than buying more electricity, if that electricity has a low local content.

To consistently evaluate these, the use of a systems model is required. Such a tool would allow for the relative roles of $\mathrm{EE}$, renewable energy and gas-based electricity generation to be consistently quantified.

Limitations also arise due to assumptions made for the analysis. We discussed them while describing the model and summarise them here. Average values were assumed for wages, constant across sectors. Secondly, one fixed number of jobs per unit of activity was assumed for each sector. Further the 10 captures only a snapshot in time. A systems model will allow for aspects of the IO's static nature to be overcome. For example:

- Electricity system expansion is associated with changes that are not reflected in the historical system represented in the country's 10 table. This is particularly the case where new 'business-as-usual' investments might be displaced by others such as EE or renewable energy.

Seen in isolation investment in the latter (depending on the local content and cost assumptions) might appear as a costly interventions as it 'takes away' revenue that would otherwise go to the power sector. But not shown in the $\mathrm{IO}$ is that electricity production needs to increase over time (with a growing economy). Accordingly, EE reduces sales, but it also reduces costs associated with having to meet new (intermediate and final) consumption.

If it did not do this, the alternative (to investing in EE) is to invest in new power production. And while there are positive flows into the power sector to build more stations, this is paid for from an increased tariff burden on the economy.

Accounting for dynamic change over time, EE investments allow us to avoid new costs and reallocate financial flows more efficiently.

- An energy systems model such as OSeMOSYS [16] allows for consistent scenarios to be developed indicating the potential for substitution between RE, EE and gas (including fuel imports).

As indicated in the flow diagrams in this paper we therefore separate out technologies in OSeMOSYS and associate economic impact (in this case job gains and losses) to elements of the systems that are allowed to compete and substitute each other. In so doing, we create a more dynamic accounting for potential change in the system. That is the specific function of part two of this paper. Further, as all elements of this analysis are open, they allow the analyst to investigate concurrent assumptions changes in the 10 as well as the systems analysis.

\section{Declarations}

\section{Data availability}

The data supporting this analysis is openly available under license CC BY 4.0 (https://creativecommons.org/licenses/by/4.0/) and annexed to this publication.

Competing interests: The authors declare no competing interests.

\section{Author contributions}

Page 21/30 
Mark Howells: conceptualisation, methodology, data curation, visualisation, investigation, original draft preparation; Thameur Necebi: methodology, data curation; John Skip Laitner: methodology, investigation; Francesco Gardumi: data curation, visualisation, review and editing; Franziska Bock: data curation, review, editing.

\section{Acknowledgements}

This work has been produced in the scope of a project implemented by Deutsche Gesellschaft für Internationale Zusammenarbeit $(\mathrm{GIZ}) \mathrm{GmbH}$. Responsibility for the contents of this paper lies entirely with the authors and can in no way be taken to reflect the views of GIZ.

\section{References}

1. "National Appropriate Mitigation Action (NAMA) Database." http://www.nama-database.org/index.php/Tunisia (accessed Apr. 01, 2020).

2. Agence Nationale pur la Maitrise de l’Energie, "Plan Solaire Tunisien: Programmation, conditions et moyens de la mise en oevre," Tunis, Tunisia, Apr. 2012. Accessed: Apr. 01, 2020. [Online]. Available:

http://www.anme.nat.tn/fileadmin/user1/doc/DEP/Rapport_final_PST.pdf.

3. African Development Bank Group, "Tunisia Economic Outlook." https://www.afdb.org/en/countries-north-africatunisia/tunisia-economic-outlook (accessed Apr. 01, 2020).

4. OECD, “OECD Economic Surveys: Tunisia,” Mar. 2018. Accessed: Apr. 01, 2020. [Online]. Available: http://www.oecd.org/economy/tunisia-economic-snapshot/.

5. The World Bank, "Tunisia Overview." https://www.worldbank.org/en/country/tunisia/overview (accessed Apr. 01, 2020).

6. International Energy Agency, “IEA Countries and Regions: Tunisia.” https://www.iea.org/countries/Tunisia (accessed Apr. 01, 2020).

7. GIZ and ANME, "Renewable energy and energy efficiency in Tunisia - employment, qualification and economic effects," Deutsche Gesellschaft für Internationale Zusammenarbeit (GIZ) GmbH, 2012. Accessed: Apr. 07, 2020. [Online]. Available:

https://energypedia.info/images/8/85/EN_Renewable_energy_and_energy_efficiency_in_Tunisia_GIZ_2012.pdf.

8. S. Lechtenböhmer, A. Durand, M. Fischedick, A. Nebel, O. Soukup, and S. Wane, “Etude Stratégique du Mix Energétique pour la Production d’Electricité en Tunisie: Rapport Final," Wuppertal Institut für Klima, Umwelt, Energie GmbH, Wuppertal, Germany, Apr. 2012. Accessed: Apr. 02, 2020. [Online]. Available: https://epub.wupperinst.org/frontdoor/deliver/index/docld/4785/file/4785_Mix_Energetique_Tunisie.pdf.

9. S. Laitner, S. Bernow, and J. DeCicco, "Employment and other macroeconomic benefits of an innovation-led climate strategy for the United States," Energy Policy, vol. 26, no. 5, pp. 425-432, Apr. 1998, doi:

10.1016/S0301-4215(97)00160-2.

10. M. Howells, "Industrial efficiency as an economic development strategy for South Africa," presented at the International Energy Workshop, Paris, France, Jul. 2004.

11. H. WINKLER, M. HOWELLS, and K. BAUMERT, "Sustainable development policies and measures: institutional issues and electrical efficiency in South Africa," Clim. Policy, vol. 7, no. 3, pp. 212-229, Jan. 2007, doi: 10.1080/14693062.2007.9685650.

12. M. Howells, K. Jeong, L. Langlois, M. K. Lee, K.-Y. Nam, and H. H. Rogner, "Incorporating macroeconomic feedback into an energy systems model using an 10 approach: Evaluating the rebound effect in the Korean 
electricity system," Energy Policy, vol. 38, no. 6, pp. 2700-2728, 2010.

13. Y. Y. Rady, “An Integrated Energy Economic Interaction Model with Application to Egypt," 2019.

14. S. Lindner, J. Legault, and D. Guan, “Disaggregating the Electricity Sector of China's Input-Output Table for Improved Environmental Life-Cycle Assessment," Econ. Syst. Res., vol. 25, no. 3, pp. 300-320, Sep. 2013, doi: 10.1080/09535314.2012.746646.

15. OECD, “National Input-Output Tables," 2018. https://stats.oecd.org/OECDStat_Metadata/ShowMetadata.ashx? Dataset=IOTSI4_2018\&ShowOnWeb=true\&Lang=en (accessed Nov. 19, 2020).

16. M. Howells et al., "OSeMOSYS: The Open Source Energy Modeling System: An introduction to its ethos, structure and development," Energy Policy, vol. 39, no. 10, pp. 5850-5870, Oct. 2011, doi: 10.1016/j.enpol.2011.06.033.

17. L. Detoc, “RES4MED Country Profiles: Tunisia,” RES4MED, Nov. 2016. Accessed: Apr. 02, 2020. [Online]. Available: https://www.res4med.org/wp-content/uploads/2017/11/Country-Profile-TunisiaReport_05.12.2016.pdf.

18. R. Spalding-Fecher, H. Winkler, A. Dick, L. Jeftha, and J. A. Laitner, "Modeling economy-wide impacts of investments in industrial energy efficiency: a South African Case Study," Proc. ACEEE Summer Study Ind. Energy Effic., vol. 6, pp. 6-219, 2003.

19. M. Howells et al., “Energy system analytics and good governance-U4RIA goals of Energy Modelling for Policy Support," 2021.

20. S. Collins et al., "Turning FAIR into reality: Final Report and Action Plan from the European Commission Expert Group on FAIR Data," European Commission, Directorate-General for Research and Innovation, Brussels, Belgium, 2018. Accessed: Jan. 04, 2021. [Online]. Available: https://ec.europa.eu/info/sites/info/files/turning_fair_into_reality_0.pdf'.

\section{Figures}




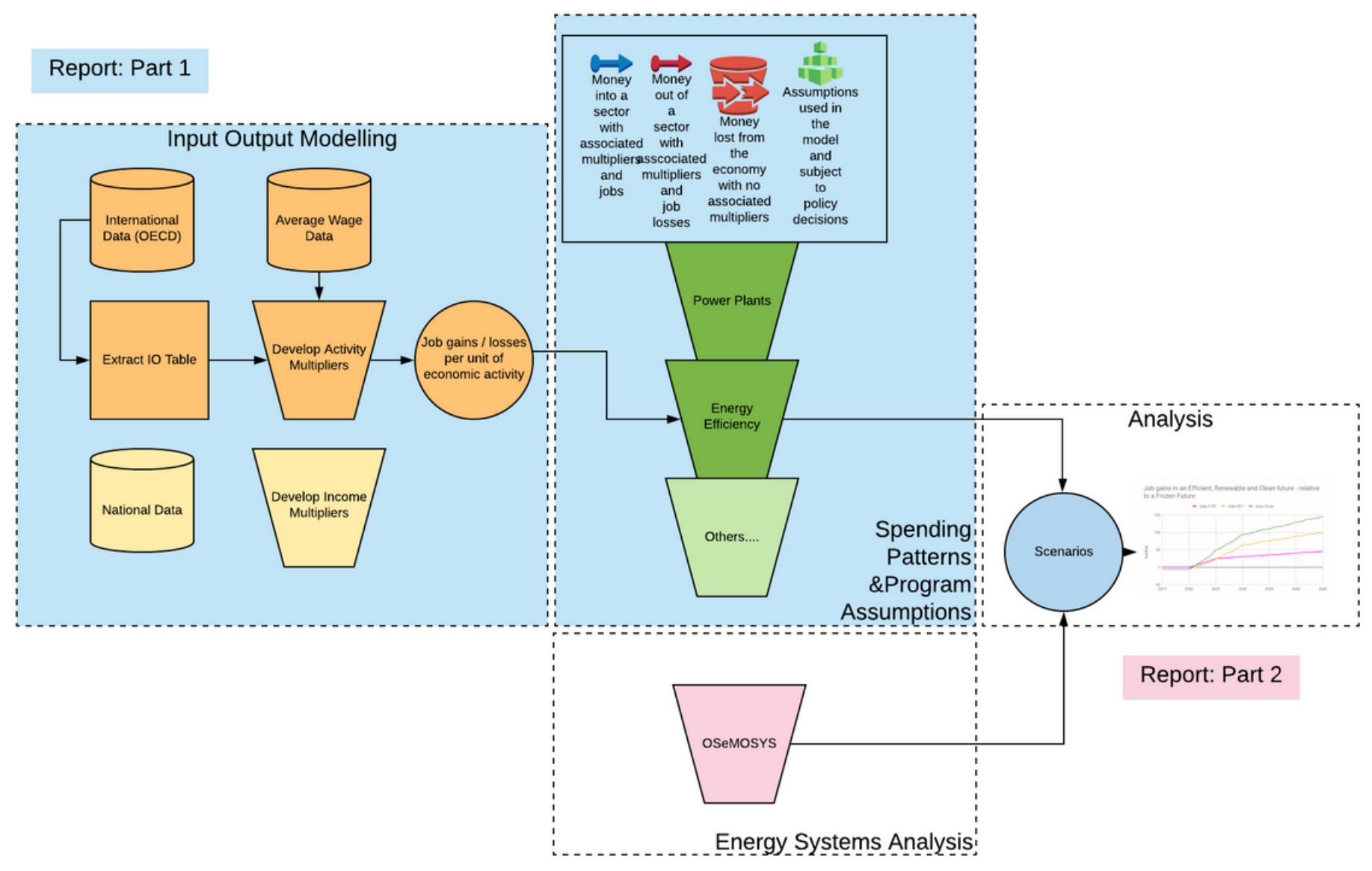

\section{Figure 1}

Integration of a simple Input-Output model with OSeMOSYS. The highlighted area indicates the scope of this paper. 


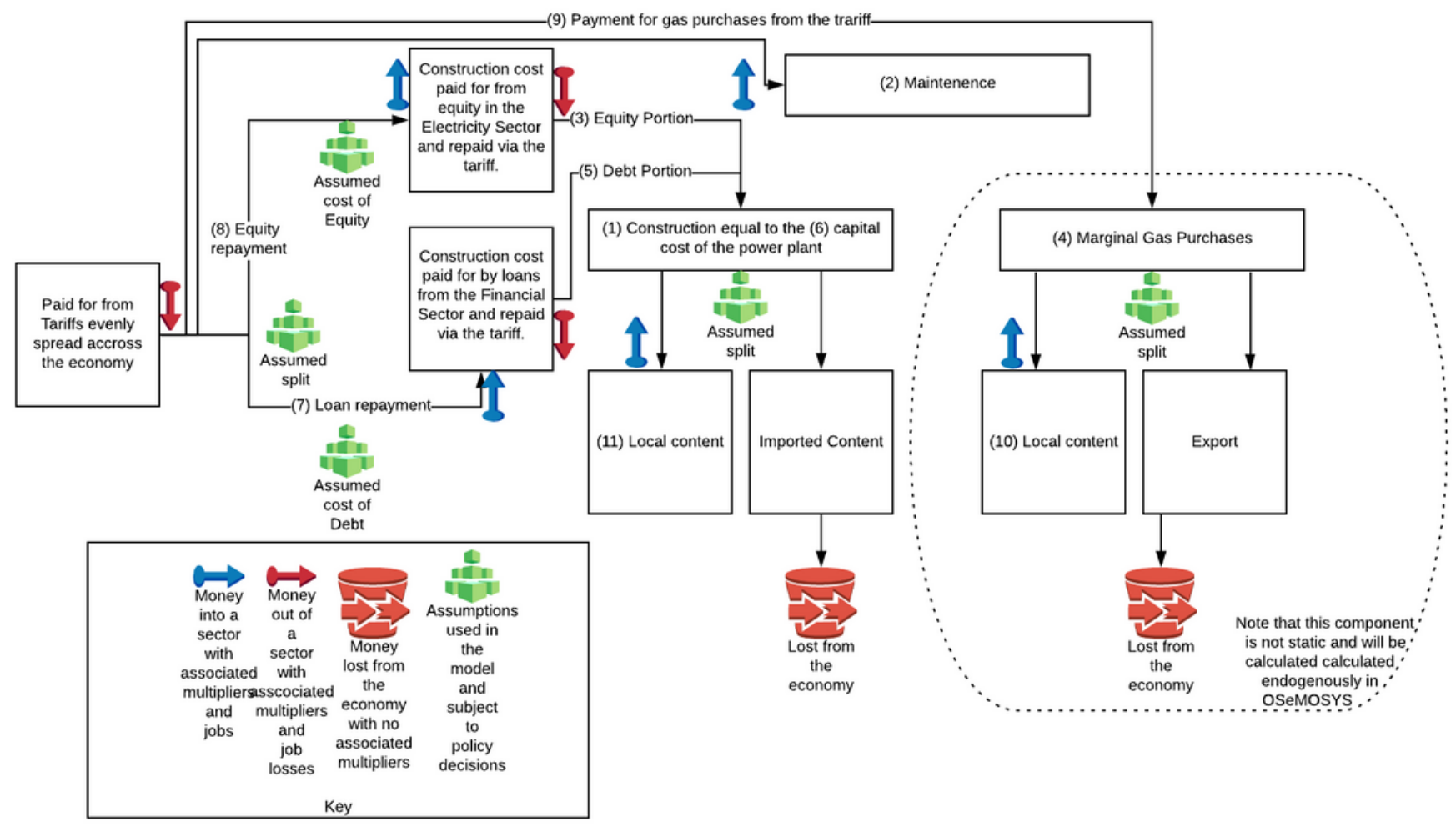

Figure 2

Economic flows associated with investment in a new power plant. 


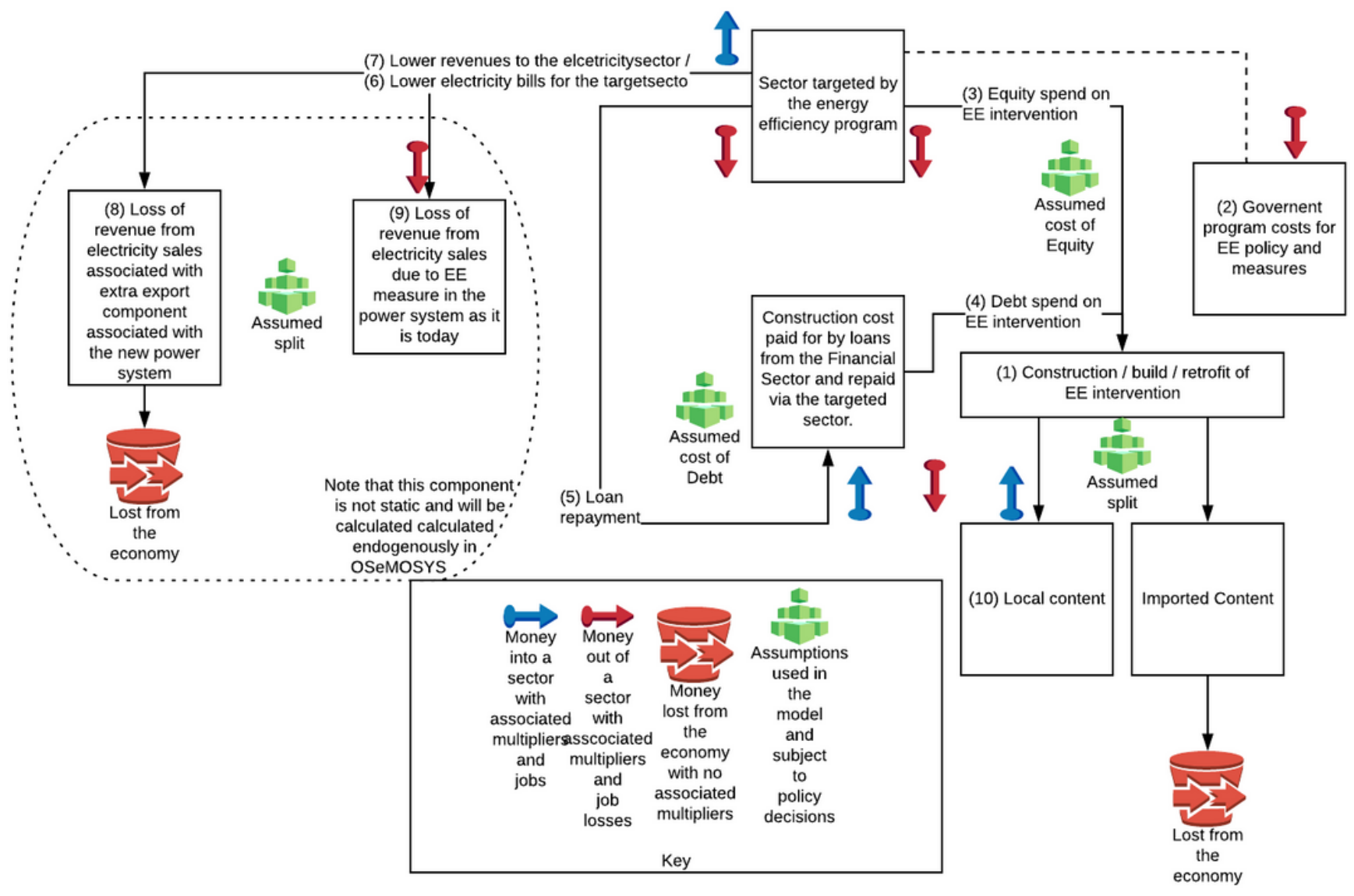

Figure 3

Economic flows associated with investment in an energy efficiency program. 


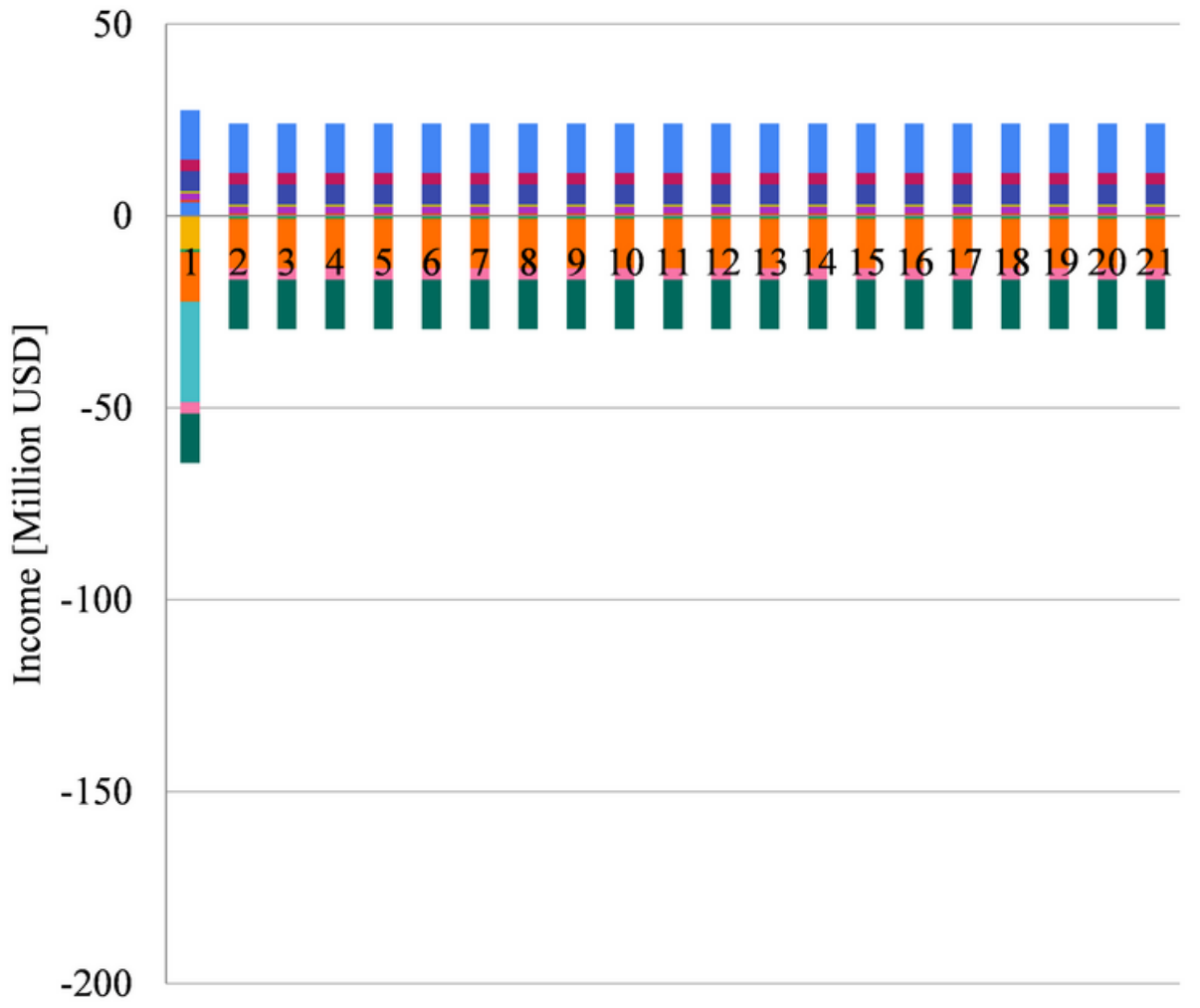

- In Tariff Revenue (fuel component) - In Tariff Revenue

- Out Elec Bills (fuel component)

n Out Elec Bills

- In Domestic Fuel Sales

- In Equity Repayment

- In Debt Repayment

- Out Debt Payment

- Out Fuel Payment

- Out O\&M Payment

- Out Equity Payment

- In Maintenence

- In Construction

Figure 4

Economic flows for a Combined Cycle Gas Turbine.

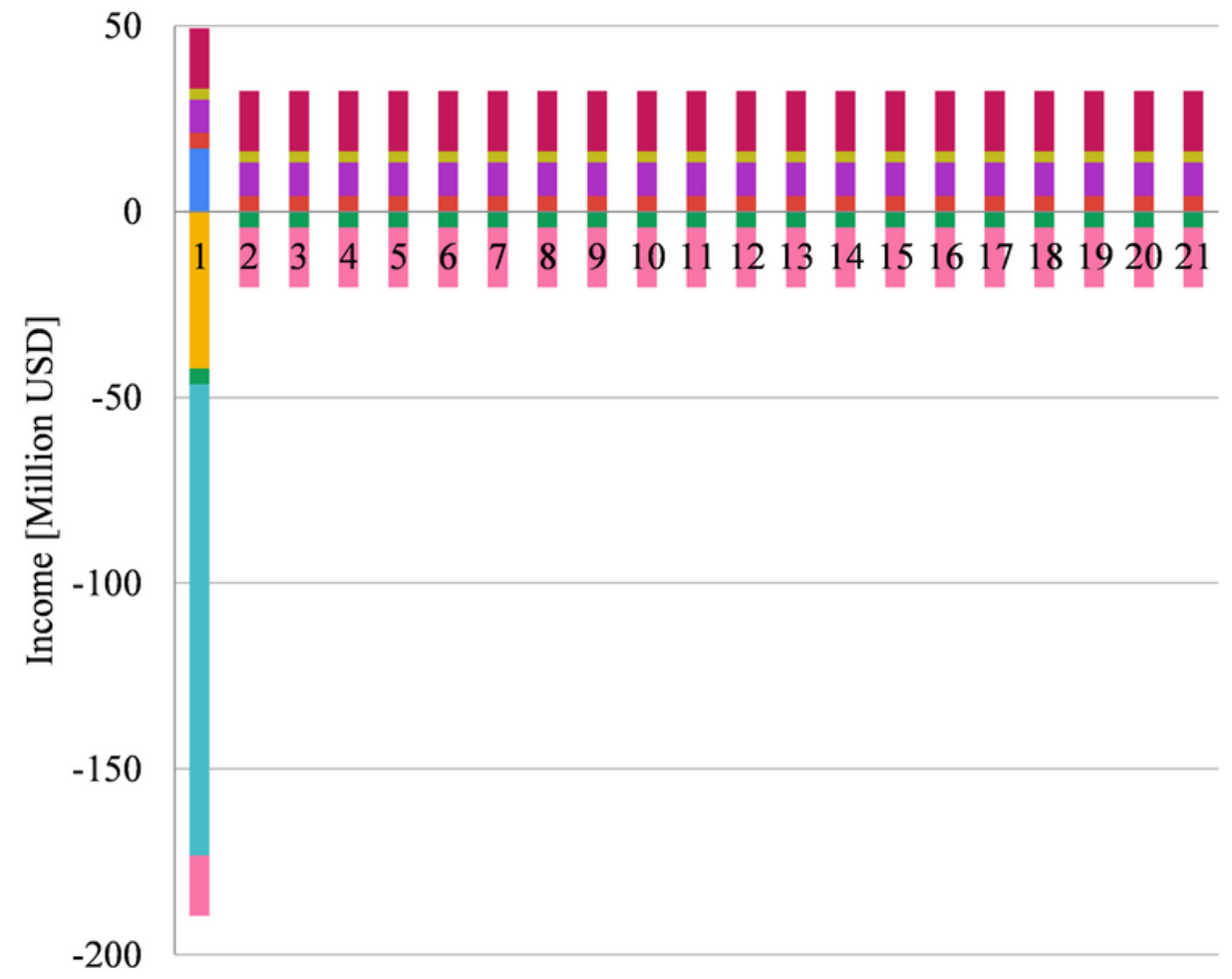

- In Tariff Revenue (fuel component)

- In Tariff Revenue

- Out Elec Bills (fuel component)

- Out Elec Bills

- In Domestic Fuel Sales

In Equity Repayment

- In Debt Repayment

- Out Debt Payment

- Out Fuel Payment

- Out O\&M Payment

- Out Equity Payment

- In Maintenence

- In Construction

Figure 5 
Economic flows for a Solar PV utility scale power plant.

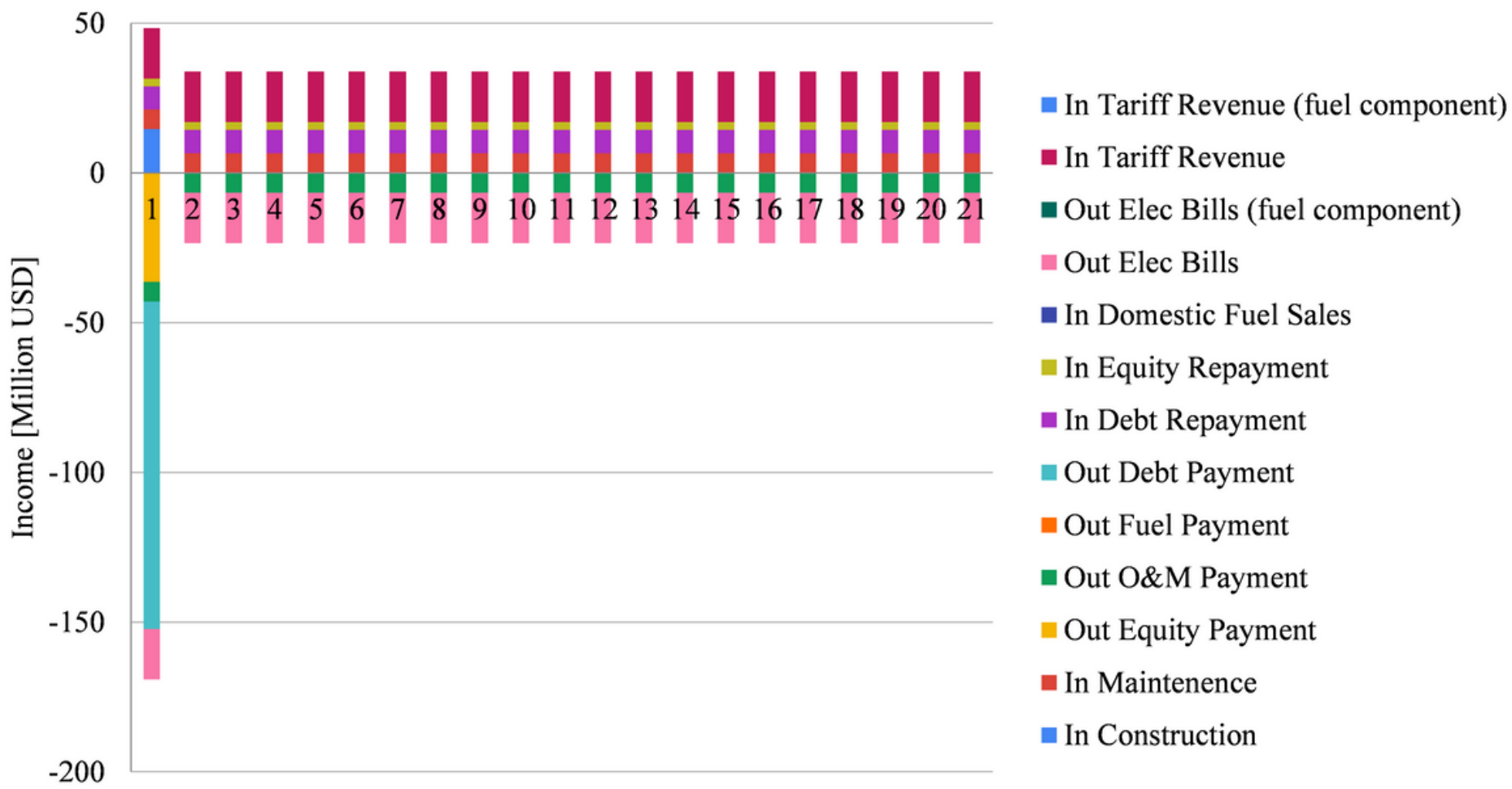

Figure 6

Economic flows for onshore wind turbines.

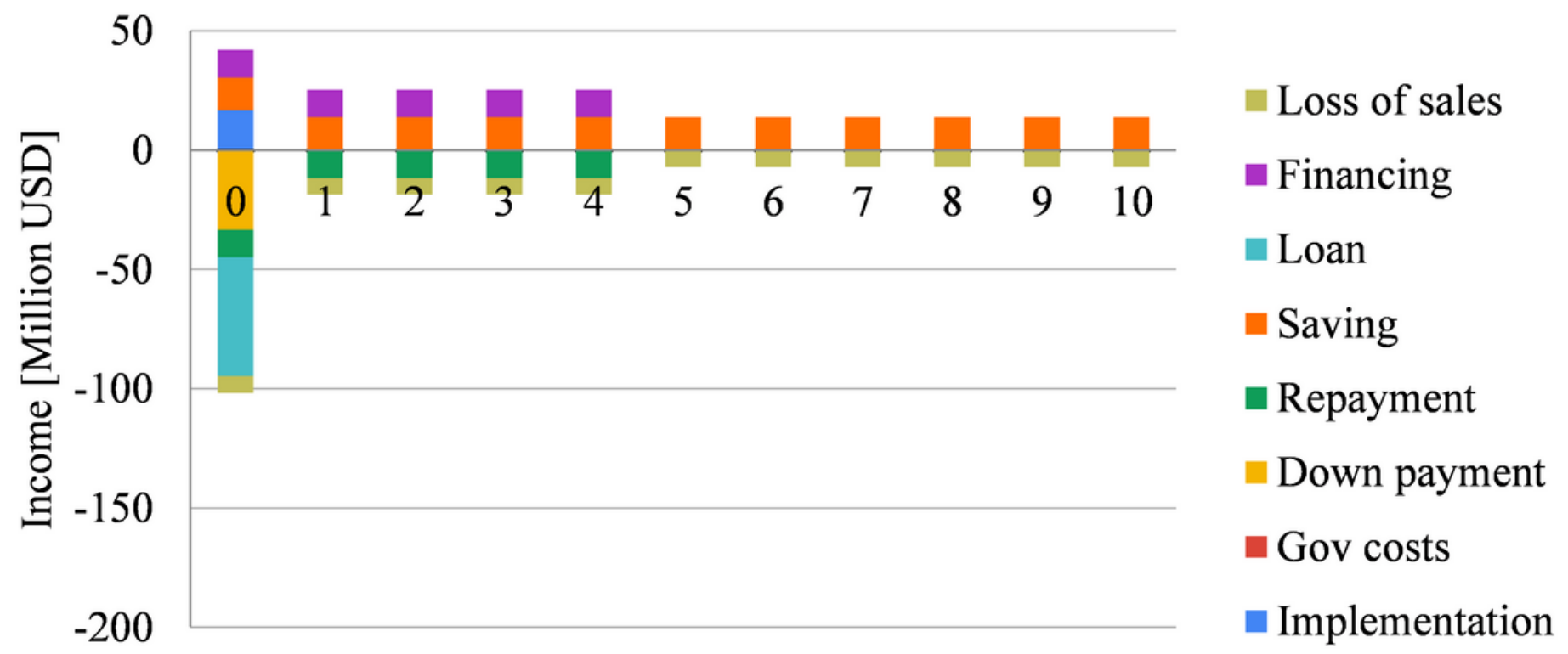

Figure 7

Economic flows for an energy efficiency intervention in the residential sector. 


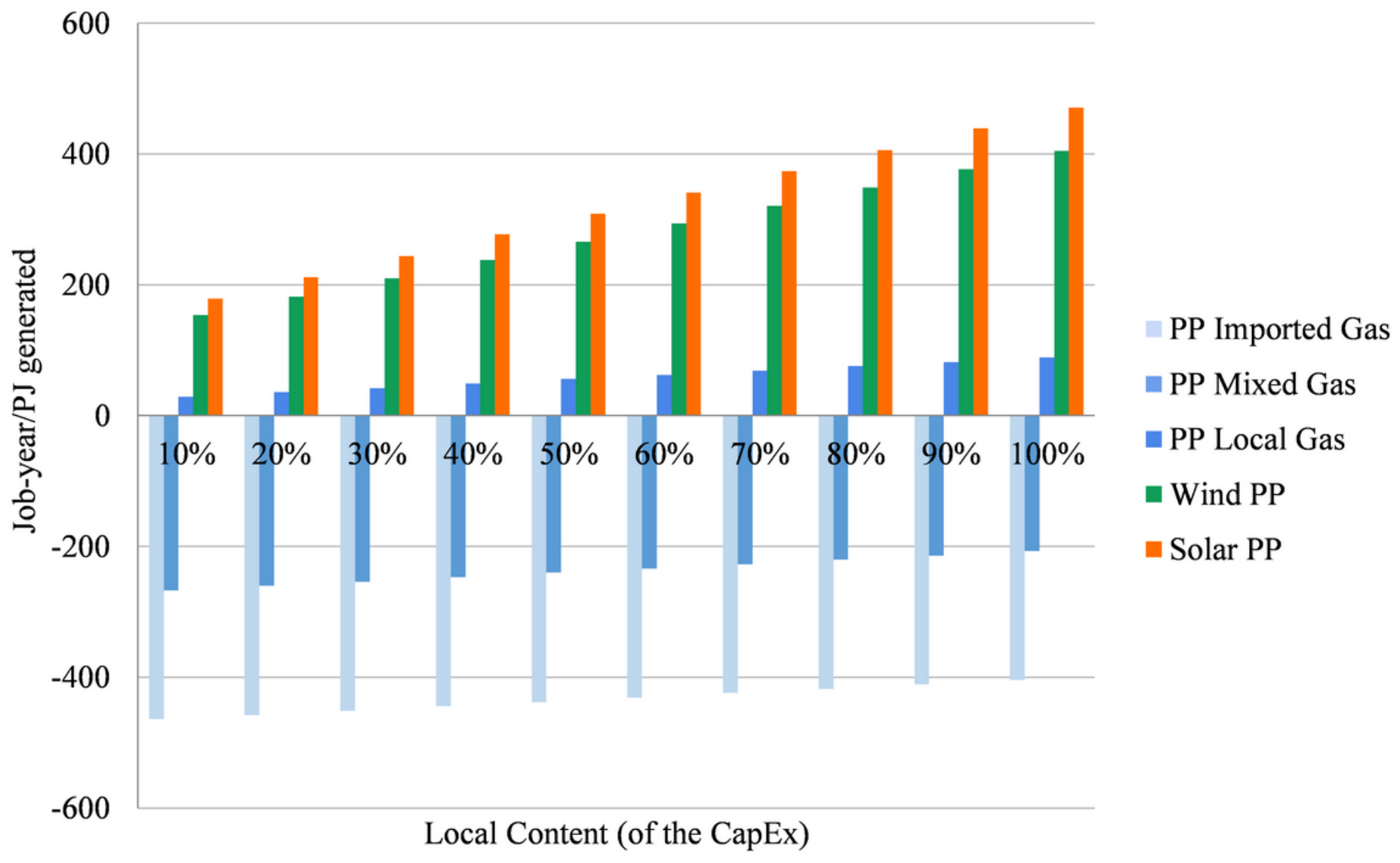

Figure 8

Job years versus local content for power plants. 


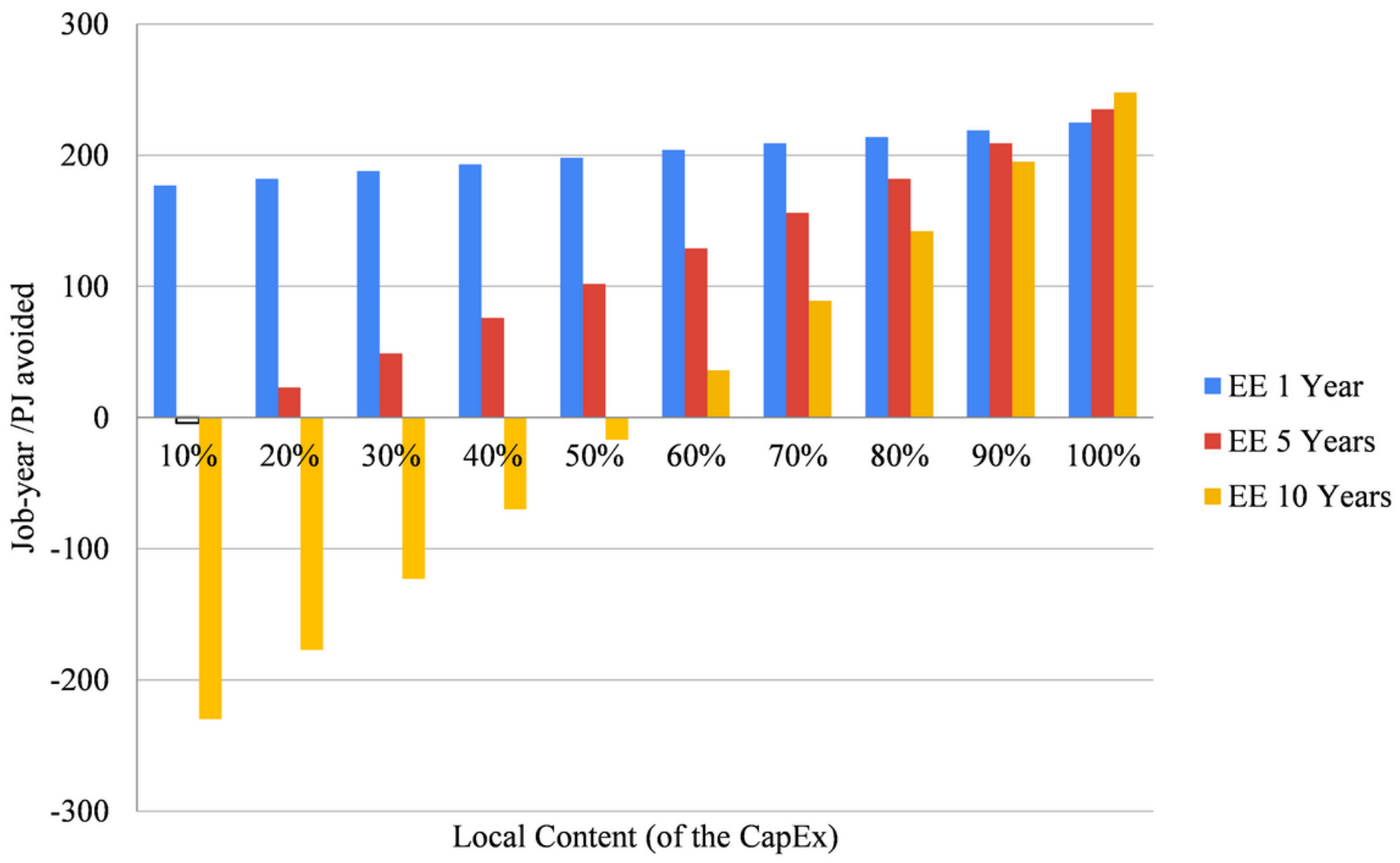

Figure 9

Job years versus local content for a residential energy efficiency program, assuming 1, 5 and 10 years payback times.

\section{Supplementary Files}

This is a list of supplementary files associated with this preprint. Click to download.

- IOModelTunisiabaselineMethodsIX.xIsx 